\title{
Mixed mobile ion effect on a.c. conductivity of boroarsenate glasses
}

\author{
M PURNIMA, SHASHIDHAR BALE, CH SRINIVASU, M A SAMEE and SYED RAHMAN* \\ Department of Physics, Osmania University, Hyderabad 500 007, India
}

MS received 28 October 2010; revised 28 October 2011

\begin{abstract}
In this article we report the study of mixed mobile ion effect (MMIE) in boroarsenate glasses. DSC and a.c. electrical conductivity studies have been carried out for $x \mathrm{MgO}-(25-x) \mathrm{Li}_{2} \mathrm{O}-\mathbf{5 0 B}_{2} \mathrm{O}_{3}-25 \mathrm{As}_{2} \mathrm{O}_{3}$ glasses. It is observed that strength of MMIE in a.c. conductivity is less pronounced with increase in temperature and frequency. The results were explained on the basis of structural model (SM) proposed by Swenson and his co-workers supporting molecular dynamic results.
\end{abstract}

Keywords. Glass transition temperature; glasses; a.c. conductivity; mixed mobile ion effect.

\section{Introduction}

An interesting phenomenon observed in glasses is the so called mixed alkali effect (MAE). Glasses containing two types of alkali ions exhibit highly nonlinear variations of properties when one type of alkali is systematically substituted by the other (Day 1976; Ingram 1987). The most evident manifestation of this effect has been observed in the measured ionic conductivity and diffusion coefficient of glasses (Hunt 1999; Imre et al 2002). The same behaviour is often exhibited when alkali ion is substituted by an isovalent non-alkali ion also, and is referred to as mixed mobile ion effect (MMIE). The strength of MAE depends on many factors (Isard 1969; Day 1976; Moynihan 1979; Maass et al 1992; Jain and Lu 1996; Cramer and Gao 2005; Gao and Cramer 2005), e.g. temperature, total alkali content, size and mass difference of the involved alkali ions, etc. Several models have been proposed to explain the 'anomalous' conductivity behaviour during the mixing of two monovalent cations (Isard 1969; Day 1976; Ingram 1987). These models assume either large structural modification induced by mixing mobile species of different sizes or specific interaction between these dissimilar mobile species. Greaves et al (1990) in EXAFS study indicated that the environment of the mobile cations in glasses is well determined by the type of cation that creates the site it occupies. Based on these results, Bunde et al $(1991,1994)$ proposed a new model for ionic migration in glasses, called the dynamic structural model (DSM). The main idea of the DSM model is the existence of mismatches between different types of sites designated by cations in the glass. Ion migration is associated with a "memory effect" of the sites previously occupied, which leads to the creation of ionic pathways. Hunt (1997) applied the theory of percolative transport to the MAE and predicted disappearance of mixed alkali effect when temperature is raised.

\footnotetext{
*Author for correspondence (syedrahman848@yahoo.co.in)
}

Glasses containing $\mathrm{As}_{2} \mathrm{O}_{3}$ as main glass former has been studied during last two decades (Chowdari and Akhter 1990; Srinivasa Rao and Veeraiah 2001; Ardelean et al 2004; Ragavaiah et al 2004a,b). To our knowledge all studies are focused on the glass system containing single alkali arsenate glasses (Chowdari and Akhter 1988, 1990) and alkalifree arsenate glasses (Nicula et al 1986; Srinivasa Rao and Veeraiah 2002; Ragavaiah et al 2004a,b). For the first time the authors reported the optical absorption and ESR studies of copper doped mixed alkali boroarsenate glasses (Srinivasa Rao et al 2005) and also the mixed alkali effect in $\mathrm{K}_{2} \mathrm{O}-\mathrm{Na}_{2} \mathrm{O}-\mathrm{B}_{2} \mathrm{O}_{3}-\mathrm{As}_{2} \mathrm{O}_{3}$ glasses (Srinivasa $\mathrm{Rao}$ et al 2007). Recently, Ardelean et al (2008, 2010) investigated the arsenate containing glasses by Raman and infrared spectroscopy. However, other than this no mixed alkali effect studies were reported on arsenate glasses.

Many investigations have been reported on MAE in d.c. electrical conductivity of glasses (Ghosh and Ghosh 2002; Mansour 2005; Gao 2006). For the first time Kulkarni et al (2000) reported MAE in the a.c. conductivity of glasses. In the present study, we investigate the mixed mobile ion effect in $x \mathrm{MgO}-(25-x) \mathrm{Li}_{2} \mathrm{O}-50 \mathrm{~B}_{2} \mathrm{O}_{3}-25 \mathrm{As}_{2} \mathrm{O}_{3}$ glasses by measuring the a.c. conductivity as a function of compositional parameter, $R_{\mathrm{Mg}}$, defined as $R_{\mathrm{Mg}}=$ $\mathrm{MgO}$ mole $\% /\left(\mathrm{MgO}+\mathrm{Li}_{2} \mathrm{O}\right)$ mole $\%$, taking the values of $0,0 \cdot 2,0.4,0.6,0.8$ and 1 . The presence of alkali and alkaline earth oxides and their role in conductivity increases the interest in the present study. The authors also report DSC measurements on the present glass system.

\section{Experimental}

Glass samples of composition, $\quad x \mathrm{MgO}-(25-x) \mathrm{Li}_{2} \mathrm{O}-$ $50 \mathrm{~B}_{2} \mathrm{O}_{3}-25 \mathrm{As}_{2} \mathrm{O}_{3}$ (mole $\left.\%\right)(0 \leq x \leq 25)$, were prepared using the conventional melt-quench technique. Glasses were prepared by mixing the required proportions of the reagent grade chemicals, $\mathrm{Li}_{2} \mathrm{CO}_{3}, \mathrm{H}_{3} \mathrm{BO}_{3}, \mathrm{As}_{2} \mathrm{O}_{3}$ (May and 
Baker) and $\mathrm{MgO}$ (Fluka) in an electrical furnace using silica crucibles. The furnace temperature was varied from 1000$1150{ }^{\circ} \mathrm{C}$ depending on the glass composition. The liquids were swirled frequently to ensure homogeneous mixture. In this technique, the clear liquid (free of bubbles) is quickly cast in a stainless steel mould kept at $200{ }^{\circ} \mathrm{C}$ and pressed with another steel disc maintained at the same temperature. All the glass samples were annealed at $200{ }^{\circ} \mathrm{C}$ for a duration of about $12 \mathrm{~h}$. The glass composition mentioned was the nominal glass composition. The actual composition was calculated from the exact masses of the components in the glass batch, assuming that the glass composition does not change during melting. For samples taken from different regions of the bulk specimen, the absence of any Bragg peaks in the X-ray diffraction pattern confirmed that they were amorphous and homogeneous.

The thermal behaviour of the glass samples was investigated using a differential scanning calorimeter (TA Instruments DSC 2010). Samples in the form of powder weighing about $15 \mathrm{mg}$ were sealed in copper pans and scanned through their melting temperature with a heating rate of $10^{\circ} \mathrm{C} / \mathrm{min}$. During all runs the sample chamber was purged with dry nitrogen.

A.C. conductivity measurements were carried out using AUTOLAB (PGSTAT 30) low frequency impedance analyser interfaced to a PC using a frequency response analyser (FRA) software. Parallel glass discs of thickness around $1.5 \mathrm{~mm}$ and diameter $12 \mathrm{~mm}$ were grounded and polished. The flat surfaces of the samples were painted with silver paste. The samples were scanned in the frequency range $100 \mathrm{~Hz}-1 \mathrm{MHz}$ and in the temperature range $300-573 \mathrm{~K}$.

\section{Results and discussion}

Figure 1 shows a typical DSC thermogram of $x \mathrm{MgO}-$ $(25-x) \mathrm{Li}_{2} \mathrm{O}-50 \mathrm{~B}_{2} \mathrm{O}_{3}-25 \mathrm{As}_{2} \mathrm{O}_{3}$ glasses at a heating rate of $10{ }^{\circ} \mathrm{C} / \mathrm{min}$. Thermodynamical and glass stability

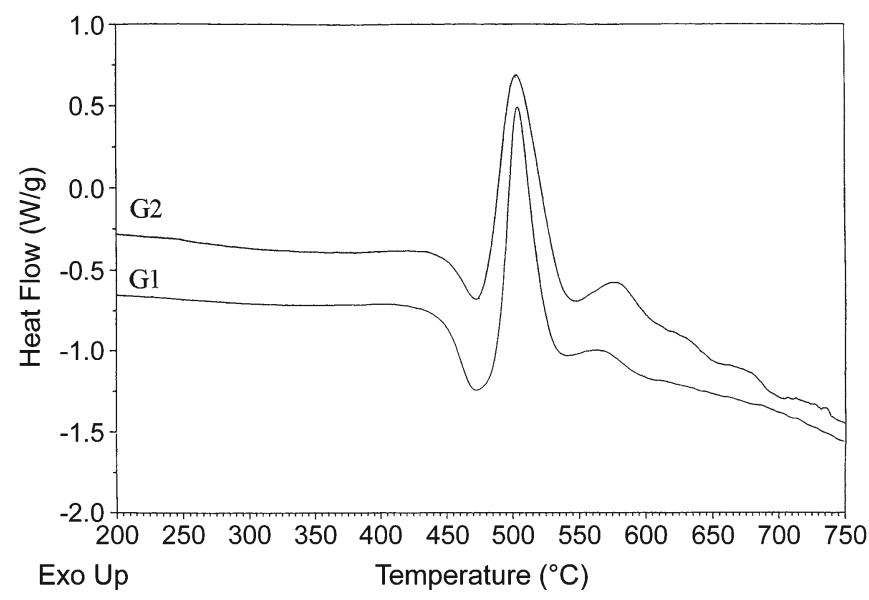

Figure 1. DSC thermograms of $G 1$ and $G 2$ glasses. parameters such as glass transition temperature, onset of crystallization temperature, peak temperature of crystallization, melting temperature (determined using Kauzman rule) were evaluated using standard procedures. DSC thermogram shows a single endothermic glass transition peak and a single exothermic crystallization peak. There is an increase of glass transition temperature by about $76^{\circ} \mathrm{C}$ as the $\mathrm{MgO}$ content is increased.

The empirical parameters used to parametrize stability of the glass are the glass stability, $S$, defined as the difference between the onset of crystallization temperature and the glass transition temperature and the Hruby parameter defined as

$$
K_{\mathrm{gl}}=\left(T_{\mathrm{c}}-T_{\mathrm{g}}\right) /\left(T_{\mathrm{m}}-T_{\mathrm{c}}\right) .
$$

The Hruby parameter characterizes the tendency of the melts to form glass. The thermodynamical parameters of the present glass system are given in table 1 .

The glass transition temperature, $T_{\mathrm{g}}$, as a function of glass composition is shown in figure 2. From the above figure it is clear that the transition temperature exhibits a negative deviation from linearity, a distinct feature of MMIE. The strength of the mixed mobile ion effect in $T_{\mathrm{g}}$ can be defined as (Gao 2006)

$$
\Delta T_{\mathrm{g}}=T_{\mathrm{g}, \mathrm{lin}}-T_{\mathrm{g}, \min },
$$

where $\Delta T_{\mathrm{g}}$ and $T_{\mathrm{g}, \min }$ represent strength of the mixed mobile ion effect in $T_{\mathrm{g}}$ and the minimum value, respectively. $T_{\mathrm{g}, \text { lin }}$ is determined at the composition which corresponds to $T_{\mathrm{g}, \min }$ and it is obtained by the linear interpolation between the glass transition temperature of the two end members. The magnitude of the mixed mobile ion effect in $T_{\mathrm{g}}$ calculated by (1) for the mixed $\mathrm{Mg} / \mathrm{Li}$ glasses is $20^{\circ} \mathrm{C}$. Similar observations were found in mixed alkali glasses (Gao 2006).

We have analysed the frequency dependence of conductivity for all the glasses as isotherms in the log-log plots. At low temperatures only a.c. conductivity was observed. As the temperature was increased, the dynamic conductivity showed a typical behaviour: a frequency independent plateau and a power law increase at high frequency. Figure 3 shows double logarithmic plots of complex conductivity at $473 \mathrm{~K}$. The plateau of conductivity spread over several decades in the medium frequency range corresponding to d.c. conductivity. All the glasses showed typical power-law behaviour. The variation of a.c. conductivity at $1 \mathrm{kHz}, 100 \mathrm{kHz}$ and $1 \mathrm{MHz}$ with the compositional parameter, $R_{\mathrm{Mg}}$, is illustrated in figure 4 . It is interesting to note that the a.c. conductivity goes through a minimum at $R_{\mathrm{Mg}}=0.4$, a distinct feature of mixed mobile ion effect. The strength of the mixed mobile ion effect decreases with increase in frequency. The temperature dependence of a.c. conductivity at $1 \mathrm{kHz}$ is depicted for all mixed mobile ion compositions in figure 5. At higher temperatures, compositions with high conductivity, $G 1$ and $G 2$, show Arrhenius behaviour and at low temperatures, a.c. conductivity shows only a weak temperature dependence. The inset shows the variation of $\sigma_{\mathrm{ac}}(1 \mathrm{kHz})$ with composition at $473 \mathrm{~K}, 523 \mathrm{~K}$ and $573 \mathrm{~K}$. Again the a.c. conductivity shows a minimum with composition confirming the observation in 
Table 1. Thermodynamical and glass stability parameters of present glass system.

\begin{tabular}{lccccccc}
\hline Glas no. & Glass composition & $T_{\mathrm{g}}$ & $T_{\mathrm{c}}$ & $T_{\mathrm{p}}$ & $T_{\mathrm{m}}$ & $S$ & $K_{\mathrm{gl}}$ \\
\hline $\mathrm{G} 1$ & $25 \mathrm{Li}_{2} \mathrm{O}-50 \mathrm{~B}_{2} \mathrm{O}_{3}-25 \mathrm{As}_{2} \mathrm{O}_{3}$ & 448 & 475 & 505 & 806 & 27 & $0 \cdot 083$ \\
$\mathrm{G} 2$ & $5 \mathrm{MgO}-20 \mathrm{Li}_{2} \mathrm{O}-50 \mathrm{~B}_{2} \mathrm{O}_{3}-25 \mathrm{As}_{2} \mathrm{O}_{3}$ & 443 & 478 & 504 & 802 & 34 & $0 \cdot 105$ \\
$\mathrm{G} 3$ & $10 \mathrm{MgO}-15 \mathrm{Li}_{2} \mathrm{O}-50 \mathrm{~B}_{2} \mathrm{O}_{3}-25 \mathrm{As}_{2} \mathrm{O}_{3}$ & 452 & 530 & 550 & 817 & 77 & $0 \cdot 269$ \\
$\mathrm{G} 4$ & $15 \mathrm{MgO}-10 \mathrm{Li}_{2} \mathrm{O}-50 \mathrm{~B}_{2} \mathrm{O}_{3}-25 \mathrm{As}_{2} \mathrm{O}_{3}$ & 465 & 635 & 676 & 839 & 169 & $0 \cdot 831$ \\
$\mathrm{G} 5$ & $20 \mathrm{MgO}-5 \mathrm{Li}_{2} \mathrm{O}-50 \mathrm{~B}_{2} \mathrm{O}_{3}-25 \mathrm{As}_{2} \mathrm{O}_{3}$ & 490 & 690 & - & 872 & 199 & $1 \cdot 092$ \\
$\mathrm{G} 6$ & $25 \mathrm{MgO}-50 \mathrm{~B}_{2} \mathrm{O}_{3}-25 \mathrm{As}_{2} \mathrm{O}_{3}$ & 519 & 725 & - & 915 & 206 & $1 \cdot 084$ \\
\hline
\end{tabular}

$T_{\mathrm{g}}$, Glass transition temperature $\left({ }^{\circ} \mathrm{C}\right) ; T_{\mathrm{c}}$, crystallization temperature $\left({ }^{\circ} \mathrm{C}\right) ; T_{\mathrm{p}}$, peak temperature of crystallization $\left({ }^{\circ} \mathrm{C}\right) ; T_{\mathrm{m}}$, melting temperature $\left({ }^{\circ} \mathrm{C}\right) ; S=\left(T_{\mathrm{c}}-T_{\mathrm{g}}\right)$, glass stability $\left({ }^{\circ} \mathrm{C}\right)$; $K_{\mathrm{gl}}=\left(T_{\mathrm{c}}-T_{\mathrm{g}}\right) /\left(T_{\mathrm{m}}-T_{\mathrm{c}}\right)$, Hruby parameter.

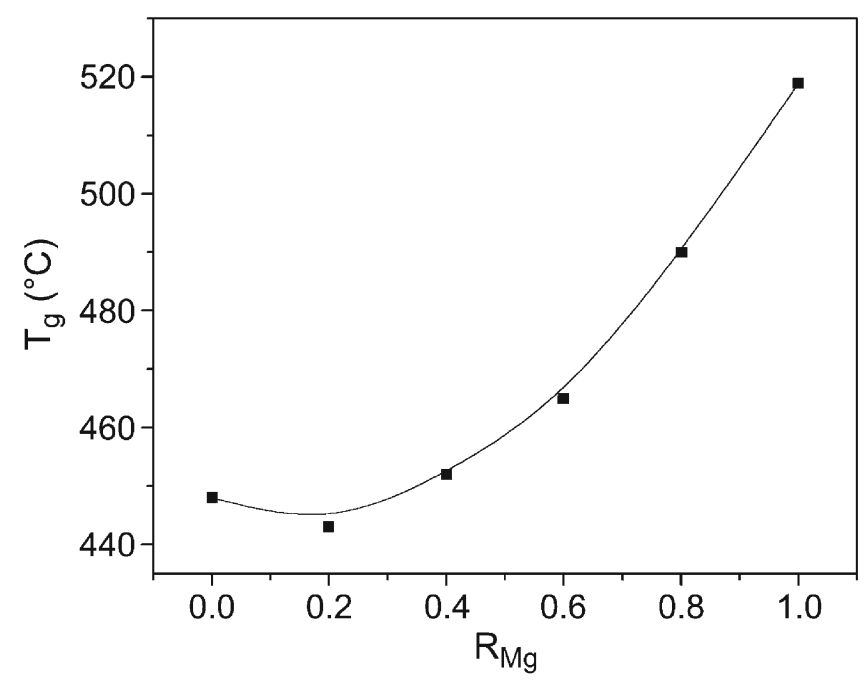

Figure 2. Compositional dependent glass transition temperature of $x \mathrm{MgO}-(25-x) \mathrm{Li}_{2} \mathrm{O}-50 \mathrm{~B}_{2} \mathrm{O}_{3}-25 \mathrm{As}_{2} \mathrm{O}_{3}$ glasses.

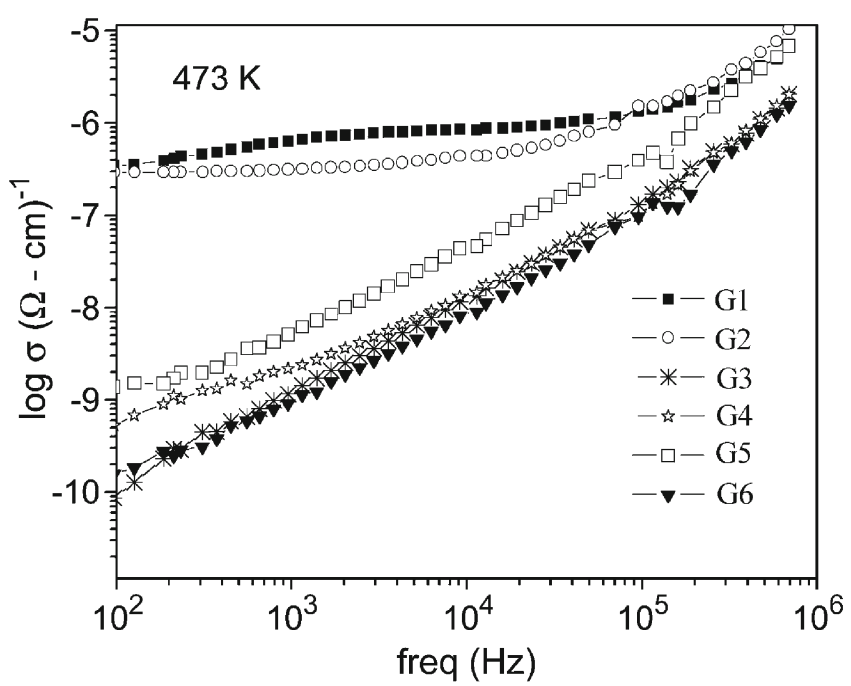

Figure 3. Double logarithmic plots of frequency dependent conductivity for $x \mathrm{MgO}-(25-x) \mathrm{Li}_{2} \mathrm{O}-50 \mathrm{~B}_{2} \mathrm{O}_{3}-25 \mathrm{As}_{2} \mathrm{O}_{3}$ glasses at $473 \mathrm{~K}$.

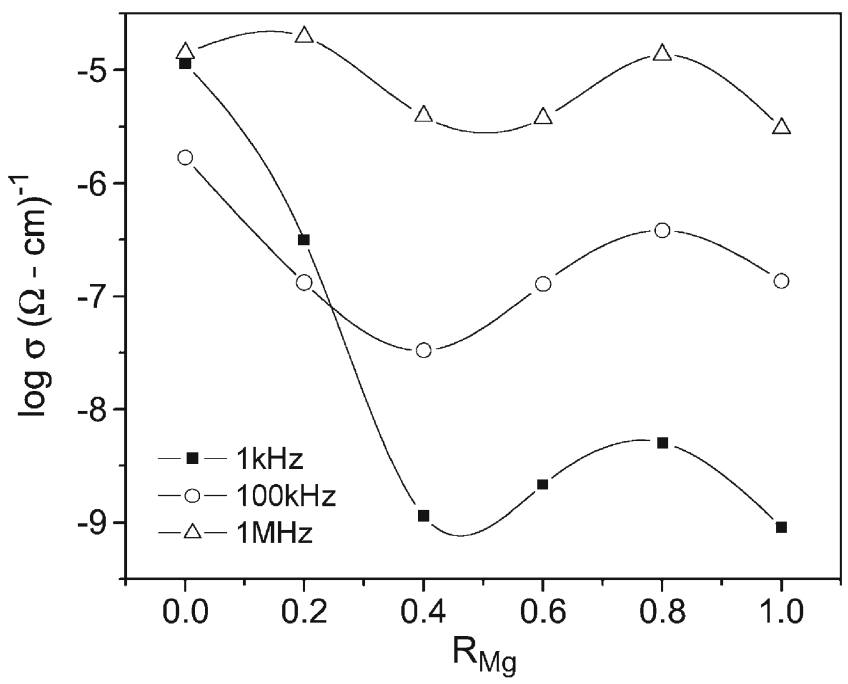

Figure 4. Variation of a.c. conductivity with compositional parameters at $1 \mathrm{kHz}, 100 \mathrm{kHz}$ and $1 \mathrm{MHz}$.

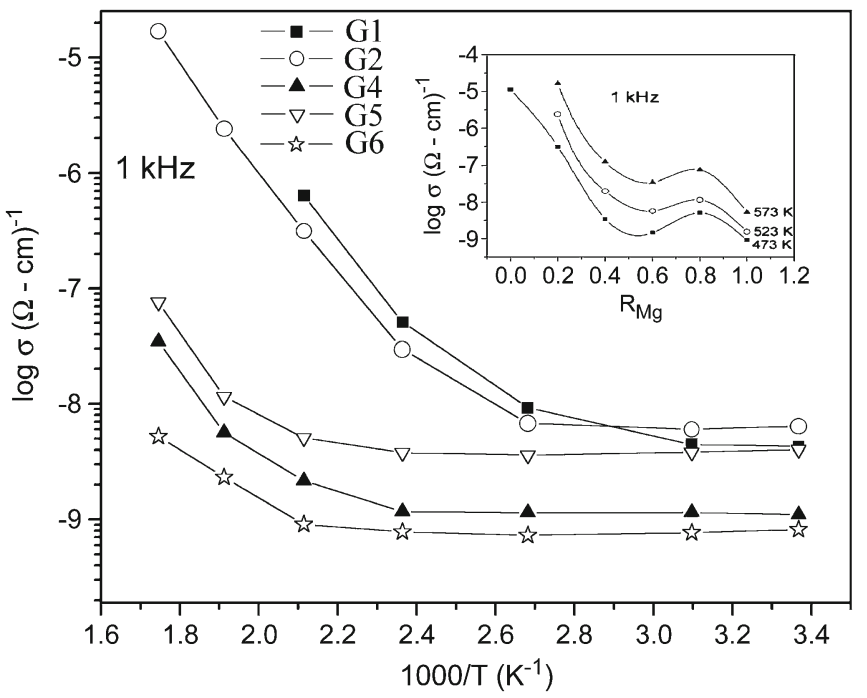

Figure 5. Variation of a.c. electrical conductivity plotted in Arrehenius coordinates for all glasses at $1 \mathrm{kHz}$. Inset shows isothermal conductivity plots at $473 \mathrm{~K}, 523 \mathrm{~K}$ and $573 \mathrm{~K}$. 
figure 4. The strength of MMIE decreases with increase in temperature.

Since mixed alkali behaviour is often referred to as mixed mobile ion effect (MMIE), the results of the present investigation are interpreted on the basis of structural model (SM) proposed by Swenson and his co-workers (Swenson et al 2001; Swenson and Adams 2003; Adams and Swenson 2004), of which the essential ideas are shortly summarized in the following. The structure model is constructed directly from experimental data of mixed mobile ion glasses, and by applying the bond-valence method to reverse Monte Carlo simulations. The model suggests that the two types of alkali ions in mixed alkali glasses are randomly mixed and tend to attain the same local structural environment as in the single alkali glasses. The two types of alkali ions have distinctly different low dimensional conduction pathways. This results in a large energy mismatch for ions jumping between dissimilar alkali sites (Uchino et al 1992). The mixed alkali effect is mainly due to large mismatch between the local potentials of site $A$ and the induced potential of ion $B$, as reflected by a high activation energy for ion jumps to dissimilar sites, viz. $A$ ions tend to block the pathways for $B$ ions and vice versa. Various recent molecular dynamic simulations (Jund et al 2001; Habasaki and Hiwatari 2002) have independently confirmed that the large energy mismatch is basically independent of compositions.

When analysed in terms of the structural model, the $\mathrm{Li}^{+}$ and $\mathrm{Mg}^{2+}$ ions in the mixed $\mathrm{Li} / \mathrm{Mg}$ glasses are taken to be randomly mixed in all the conduction pathways. This random mixing, coupled with the mismatch, results in highly effective blocking of $\mathrm{Li}$ pathways by $\mathrm{Mg}$ ions, and vice versa. This blocking considerably reduces the long range mobility of both $\mathrm{Li}^{+}$and $\mathrm{Mg}^{2+}$ ions in comparison to the corresponding single component $\mathrm{Li}$ and $\mathrm{Mg}$ glasses. These effects result in a lower conductivity for mixed $\mathrm{Li} / \mathrm{Mg}$ glasses relative to their corresponding single component $\mathrm{Li}$ and $\mathrm{Mg}$ glasses, producing the mixed mobile ion effect shown in figures 4 and 5 .

\section{Conclusions}

The glass transition temperature and a.c. electrical conductivity of $\mathrm{MgO}-\mathrm{Li}_{2} \mathrm{O}-\mathrm{B}_{2} \mathrm{O}_{3}-\mathrm{As}_{2} \mathrm{O}_{3}$ glasses has been investigated. For the first time, mixed mobile ion effect has been detected in the a.c. conductivity of glasses. The strength of the effect decreases with the increase in temperature and also with frequency. MMIE is interpreted on the basis of structural model proposed by Swenson and co-workers.

\section{References}

Adams S and Swenson J 2004 Solid State Ionics 175665

Ardelean I, L R Ciceo and Filip S 2004 J. Magn. Magn. Mater. 272337

Ardelean I, Simona L and Rusu D 2008 Solid State Sci. 101384

Ardelean I, Simona L and Rusu D 2010 Physica B405 2259

Bunde A, Ingram M D, Maass P and Ngai K L 1991 J. Non-Cryst. Solids 1311109

Bunde A, Ingram M D and Maass P 1994 J. Non-Cryst. Solids 1721222

Chowdari B V R and Akhter S K 1988 Solid State Ionics 28 747

Chowdari B V R and Akhter S K 1990 J. Non-Cryst. Solids 11616

Cramer C and Gao Y 2005 Phys. Chem. Glasses 4690

Day D E 1976 J. Non-Cryst. Solids 21343

Gao Y 2006 Chem. Phys. Lett. 417430

Gao Y and Cramer C 2005 Phys. Chem. Glasses 46182

Ghosh S and Ghosh A 2002 Phys. Rev. B66 132204

Greaves G N et al 1990 WALTER, Int. Phys. Conf. Ser III 411

Habasaki J and Hiwatari Y 2002 J. Non-Cryst. Solids 307930

Hunt A 1997 J. Non-Cryst. Solids 2201

Hunt A G 1999 J. Non-Cryst. Solids 25547

Imre A W, Voss S and Mehrer H 2002 Phys. Chem. 43219

Ingram M D 1987 Phys. Chem. Glasses 28215

Isard J O 1969 J. Non-Cryst. Solids 1235

Jain H and Lu X 1996 J. Non-Cryst. Solids 196285

Jund P, Kob W and Jullien R 2001 Phys. Rev. B64 134303

Kulkarni A R, Lunkenhiemer P and Loidi A 2000 Mater. Chem. Phys. 6393

Maass P, Bunde A and Ingram M D 1992 Phys. Rev. Lett. 68 3064

Mansour E 2005 Physica $\mathbf{B 3 6 2} 88$

Moynihan C T 1979 J. Electrochem. Soc. 1262144

Nicula A L, Culea E and Milea I 1986 Mater. Chem. Phys. 14 339

Ragavaiah B V, Krishna Rao D and Veeraiah N 2004a J. Magn. Magn. Mater. 284363

Ragavaiah B V, Laxmikanth C and Veeraiah N 2004b Opt. Commun. 235341

Srinivasa Rao G and Veeraiah N 2001 J. Alloys Compd. 32752

Srinivasa Rao G and Veeraiah N 2002 J. Phys. Chem. Solids 63 705

Srinivasa Rao N, Bale S, Purnima M, Siva Kumar K and Rahman S 2005 Bull. Mater. Sci. 28589

Srinivasa Rao N, Bale S, Purnima M, Siva Kumar K and Rahman S 2007 J. Phys. Chem. Solids 681354

Swenson J and Adams S 2003 Phys. Rev. Lett. 90155507

Swenson J, Matic A, Karlsson C, Börjesson L, Meneghini C and Howells W S 2001 Phys. Rev. B63 132202

Uchino T, Sakka T, Ogata Y and Iwasaki M 1992 J. Non-Cryst. Solids 14626 